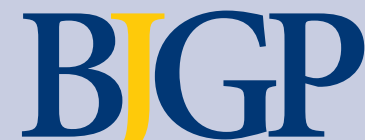

EDITOR

Roger Jones, DM, FRCP, FRCGP, FMedSci London

DEPUTY EDITOR

Alec Logan, FRCGP

Motherwell

JOURNAL MANAGER

Catharine Hull

SENIOR ASSISTANT EDITOR

Erika Niesner

ASSISTANT EDITOR

Moira Davies-Cinar

EDITORIAL ASSISTANT

Tania Marszalek

ADVERTISING EXECUTIVE

Brenda Laurent

EDITORIAL BOARD

Richard Baker, MD, FRCGP

Leicester

Stephen Barclay, MD, FRCGP, DRCOG

Cambridge

Jenny Blythe, MRCGP, DRCOG, DCH

London

Chris Butler, MD, MRCGP

Cardiff

Kath Checkland, PhD, MRCGP

Manchester

Graham Easton, MSc, MRCGP

London

Mark Gabbay, MD, FRCGP

Liverpool

Murray Lough, MD, FRCGP

Glasgow

David Mant, MD, FRCGP, FMedSci

Oxford

Nigel Mathers, MD, FRCGP, DCH

Sheffield

Tim Peters, MSc, PhD, CStat, FFPH

Bristol

Bruno Rushforth, MRCGP, DFSRH, DRCOG

Leeds

Chris Salisbury, MD, FRCGP

Bristol

John Sandars, MSc, MD, FRCGP, MRCP

Leeds

Mark Shapley, FRCGP, DCH, DRCOG

Newcastle-under-Lyme

Niroshan Siriwardena, MMedSci, PhD, FRCGP Lincoln

2009 impact factor: 2.442

EDITORIAL OFFICE

1 Bow Churchyard, London, EC4M 9DQ

(Tel: 0203188 7400, Fax: 0203188 7401).

E-mail: journal@rcgp.org.uk

http://www.rcgp.org.uk/bjgp.aspx

PUBLISHED BY

The Royal College of General Practitioners,

1 Bow Churchyard, London, EC4M 9DQ.

Registered charity number 223106. The BJGP is

published by the RCGP, but has complete

editorial independence. Opinions expressed in the

BJGP should not be taken to represent the policy

of the RCGP unless this is specifically stated.

No endorsement of any advertisement is implied or intended by the RCGP.

PRINTED IN GREAT BRITAIN BY

HPM Limited, Prime House, Park 2000, Heighington

Lane Business Park

Newton Aycliffe, Co. Durham DL5 6AR.

Printed on $100 \%$ recycled paper

ISSN 0960-1643 (Print)

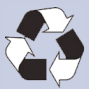

ISSN 1478-5242 (Online)

\title{
February Focus
}

\section{PATIENTS AT THE CENTRE}

As we begin to emerge from the peak period, at least in western cultures, for depressive illness, a number of authors in this month's Journal illuminate some important aspects of the recognition and management of this difficult problem. Mitchell and colleagues report the results of their European metaanalysis of diagnostic performance in primary care and identify international variation in 'diagnostic sensitivity', with Dutch primary care physicians apparently doing better than their counterparts in Australia and the US (page 110). The possible underlying explanations include differences in culture and in the organisation of health services between the countries - and the adoption of a structured system of follow-up in primary care emerges as an important variable. A particular problem, at least in the UK, in the detection of depression is identified by Harris and co-workers (page 135), who discovered that only one in five care home residents with diabetes or ischaemic heart disease had been screened for depression, compared with $66 \%$ of a comparable community sample.

One attempt to enhance the quality of depression care in the UK has been the use of severity scales, as part of the pay-forperformance Quality and Outcomes Framework (QOF). Over-concentration on the paperwork to the exclusion of the patient has already been flagged up as a concern about the QOF, ${ }^{1}$ and the qualitative study on page 117 underlines concerns about threats to individualised care and GPs' wishes to preserve professional expertise and identity. The patient-doctor interaction in the care of depression is further explored in a fascinating study by Malpass and colleagues from Bristol, UK, who identify a litany of patients' 'unvoiced agendas' in consultations about the management of depression, and coin the valuable neologism 'inverse paternalism', where the GP expects the patient to take the lead in deciding between treatments and can lead to a mismatch between perceptions and understandings, and to dysfunctional decision-making (page 108).

As multiple morbidity becomes the norm in older populations, so multiple drug prescribing becomes inevitable, and is linked, although the direction of causality is not known, to worse physical and psychological health in Kadam's study of patients aged over 50 years (page 128). The challenges posed by polypharmacy are laid out in Payne and Avery's editorial (page 83), and a number of approaches to ensuring the quality and appropriateness of multiple drug prescribing are described. These include more widespread use of medication compliance aids, as described in Lecouturier and colleagues' study (page 93), structured medication reviews, and also the involvement of other experts such as clinical pharmacists and community gerontologists as part of the extended primary healthcare team.

Many years ago the late Bruce Thomas, a GP in the south of England, developed a series of ideas about the mechanisms at play in consultations with patients without readily identifiable physical complaints. They included 'temporarily dependent patients'2 and the 'therapeutic illusion'. ${ }^{3}$ In a randomised control trial of 'being positive"4 Thomas showed how the interpersonal style of the GP affected the outcome of consultations in which a placebo was prescribed, with various degrees of confidence on the part of the prescriber. This important and controversial aspect of primary care is re-examined in an important study by Fässler and co-workers from Zurich, Switzerland, (page 101) where GPs and patients were asked about their views on the prescription of placebo drugs. As in other work on prescribing, there was a mismatch between what GPs believed patients thought and what they actually think - and in this population at least they are much more open to the informed use of placebo interventions than their doctors thought. This work demands further detailed confirmatory and explanatory research, while confirming the inseparable roles of communication and clinical skills. In a rather analogous way, the qualitative study from Lewith's group in Southampton (page 126) describes the various ways that patients and doctors can integrate complementary and alternative medicine with orthodox medical treatments.

Finally, Wilfred Treasure's account of his personal battle with his practice computer systems (page 152) will undoubtedly resonate with many readers, and heralds future articles in this Journal on the electronic patient record and its potential for research and service re-design and delivery, as well as routine patient care.

\section{Roger Jones}

Editor

\section{REFERENCES}

1. Mangin D, Toop L. The quality and outcomes framework: what have you done to yourselves? $\mathrm{Br} J \mathrm{Gen}$ Pract 2007; 57(539): 435-437.

2. Thomas KB. Temporarily dependent patients in general practice. BMJ 1974; 1(5980): 625-626.

3. Thomas KB. The consultation and the therapeutic illusion. BMJ 1978; 1(6123): 1327-1328.

4. Thomas KB. General practice consultations: is there any point in being positive? BMJ 1987; 294(6581): 1200-1202 DOI: 10.3399/bjgp11X556137

(c) British Journal of General Practice 2011; 61: 81-160. 